\title{
Analgesia through endogenous cannabinoids
}

T $\mathrm{t}$ is well known that endogen1 ous opioids act to suppress pain. New research reveals that endogenous cannabinoids likewise exist and function as stressinduced analgesics. ${ }^{1}$

The medicinal use of marijuana goes back into history as far as several thousand years, by some accounts. But it was in the 1800 s that its potential as an analgesic began to be studied, ${ }^{2}$ leading eventually to the dis-

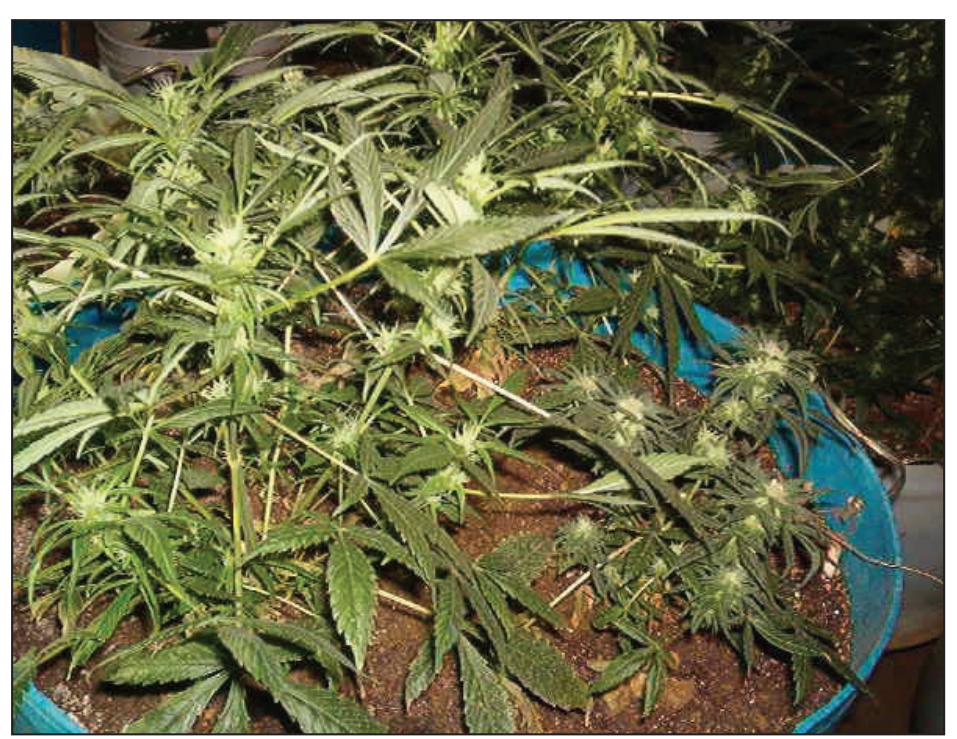

covery of $\Delta^{9}$-tetrahydrocannabinol (THC), the active component of marijuana. The discovery of this cannabinoid ignited a - search to better understand how THC affects the nervous system, and in 1990 a cannabinoid receptor, $\mathrm{CB}_{1}$, was identified in the brain. ${ }^{2}$

The discovery of the $\mathrm{CB}_{1}$ receptor spurred the discovery of endogenous cannabinoids such as anandamide (named after the Sanskrit word for bliss); ${ }^{2}$ others quickly followed, including 2arachidonoylglycerol (2-AG). These chemicals - the brain's equivalent of THC - are now collectively known as endocannabinoids.

Andrea Hohmann and colleagues ${ }^{1}$ recently showed the involvement of endocannabinoids in stress-induced analgesia. The authors created an experimental

model using rats, to which they applied painful stimuli involving a non-opioid pathway. After the authors gave the animals rimonabant, a compound that blocks $\mathrm{CB}_{1}$ receptors, they observed that the rats no longer exhibited an antinociceptive effect; that is, the animals felt more pain. Moreover, when the rats were made tolerant to the antinociceptive effects of cannabinoids (by treating the animals chronically with a compound that competes with cannabinoids), the rats began to feel pain again.

To assess whether endocannabinoids were being released by the brain as a response to pain, the investigators measured levels of anandamide and 2-AG. In the midbrain, 2-AG concentrations increased 2 minutes after a painful stimulus. This increase was followed at 7-15 minutes by the appearance of anandamide. Anandamide and 2-AG therefore have an apparent role in stress-induced relief of pain.

Finally, Hohmann's group ${ }^{1}$ created an enzyme-inhibitor that degrades 2-AG. When it was injected into the brains of the study rats, antinociception was enhanced.

Many would argue that legalizing medicinal marijuana would negate the necessity of this research. However, given the ongoing controversy around this issue, the work of Hohmann and colleagues is an important step in developing drugs that not only exploit endogenous cannabinoid pathways to treat severe pain but are free of the social stigma that accompanies illegal drugs. - David Secko, Vancouver

\section{References}

1. Hohmann AG, Suplita RL, Bolton NM, Neely MH, Fegley D, Mangieri $\mathrm{R}$, et al. An endocannabinoid mechanism for stress-induced analgesia. $\mathrm{Na}-$ ture 2005;435(7045):1108-12.

2. Piomelli D. The molecular logic of endocannabinoid signalling [review]. Nat Rev Neurosci 2003;4(11):873-84. 